\title{
Radioiodinated PARP1 tracers for glioblastoma imaging
}

Beatriz Salinas ${ }^{1}$, Christopher P. Irwin ${ }^{1}$, Susanne Kossatz ${ }^{1}$, Alexander Bolaender², Gabriela Chiosis², Nagavarakishore Pillarsetty ${ }^{1}$, Wolfgang A. Weber ${ }^{1,2,3}$ and Thomas Reiner ${ }^{1,3^{*}}$

\begin{abstract}
Background: Although the understanding of the genetic and molecular basis of cancer has advanced significantly over the past several decades, imaging and treatment options for glioblastoma patients have been more limited (N Engl J Med 359:492-507, 2008). This is in part due to difficulties in diagnosing this disease early, combined with its diffuse, infiltrative growth. This study was aimed at the development of a novel diagnostic tool for glioblastoma through the synthesis of a small molecule based on radioiodinated poly(ADP-ribose)polymerase 1 (PARP1) targeted tracers. This PARP1 is a biomarker that is overexpressed in glioblastoma tissue, but has only low expression levels in the healthy brain (Neoplasia 16:432-40, 2014).
\end{abstract}

Methods: A library of PARP1 inhibitors (iodo-PARPis) was synthesized. Based on their pharmacokinetic properties and nuclear PARP1 binding, the most successful inhibitor was radiolabeled with ${ }^{131} \mid$ and ${ }^{124}$ I. Biodistribution as well as imaging experiments were performed in orthotopic and subcutaneous mouse models of glioblastoma.

Results: One member of our iodo-poly(ADP-ribose)polymerase 1 (PARP1) inhibitor library, I2-PARPi, shows promising biophysical properties for in vivo application. All synthesized tracers have $I C_{50}$ values in the nanomolar range (9 $\pm 2-107 \pm 4 \mathrm{nM})$ and were able to inhibit the uptake of a fluorescent PARP1 inhibitor analog (PARPi-FL). 12-PARPi was able to reduce the uptake of PARPi-FL by $78 \pm 4 \%$ in vivo. In mouse models of glioblastoma, we show that the radioiodinated inhibitor analog has high uptake in tumor tissue (U251 MG xenograft, tumor, $0.43 \pm 0.06 \% \mathrm{lD} / \mathrm{g}$; brain, $0.01 \pm 0.00 \% \mathrm{lD} / \mathrm{g}$; muscle, $0.03 \pm 0.01 \% \mathrm{lD} / \mathrm{g}$; liver, $2.35 \pm 0.57 \% \mathrm{lD} / \mathrm{g}$; thyroid, $0.24 \pm 0.06 \% \mathrm{lD} / \mathrm{g}$ ). PET and SPECT imaging performed in orthotopic glioblastoma models with $\left[{ }^{124} \mid\right]$ - and $\left[{ }^{131} 1\right]-$-I2-PARPi showed selective accumulation in the tumor tissue. These results were also verified using autoradiography of tumor sections, which displayed focal selective uptake of the tracer in the tumor regions as confirmed by histology. The uptake could be blocked through pre-injection of excess unlabeled PARP1 inhibitor (Olaparib).

Conclusions: We have successfully synthesized and radioiodinated the PARP1 selective tracer I2-PARPi. The novel tracer shows selective binding to tumor tissue, both in vitro and in models of glioblastoma, and has the potential to serve as a selective PET imaging agent for brain tumors.

Keywords: PARP1; Glioblastoma; ${ }^{131}$ I; ${ }^{124}$; PET; SPECT; U87 MG; U251 MG

\footnotetext{
* Correspondence: reinert@mskcc.org

'Department of Radiology, Memorial Sloan Kettering Cancer Center, 1275

York Avenue, New York, NY 10065, USA

${ }^{3}$ Weill Cornell Medical College, New York, NY 10065, USA

Full list of author information is available at the end of the article
}

\section{Springer}

(c) 2015 Salinas et al. Open Access This article is distributed under the terms of the Creative Commons Attribution 4.0 International License (http://creativecommons.org/licenses/by/4.0/), which permits unrestricted use, distribution, and reproduction in any medium, provided you give appropriate credit to the original author(s) and the source, provide a link to the Creative Commons license, and indicate if changes were made. 


\section{Background}

State-of-the-art cancer care is stricken by our inability to efficiently treat, inhibit, and ultimately cure tumor growth for the vast majority of primary cancers. And while for most types of cancer, the diagnosis and detection of lesions has seen significant improvements over the past decades [3], some are often detected at late stages, when therapeutic options are limited. Therefore, early detection remains an unmet clinical need. This is also the case for glioblastoma, the most common cancer in the adult brain. Malignant gliomas are diffusely infiltrative, which limits the use of current diagnostic tools, typically MRI, to detect small pockets of tumor cells, which have invaded the healthy brain $[1,4-7]$. Therefore, better and more specific glioblastoma imaging agents with higher signal/noise ratios are needed, which would enable more accurate detection and delineation of infiltrative tumor regions, ultimately leading to better resection and surgical outcomes $[7,8]$. Our previous work has shown that small molecular PARP1 inhibitors, like the fluorescent PARPi-FL, accumulate in the nucleus of glioblastoma cells at high concentrations and with high specificity [2]. PARP1 is a near-ideal imaging target for glioblastoma. It holds a unique role in maintaining the integrity of the genome, and the enzyme is one of the key players responsible for DNA repair [7, 9-11]. As a cellular response to DNA damage, PARP1 is activated [12-15]. Due to rapid proliferation, genetic instability, and metabolic stress, DNA damage is more likely to happen in cancer cells than healthy tissue [11]. As a result, PARP1 is highly overexpressed in various forms of cancer [16-21]. This is particularly apparent in mouse models of glioblastoma, where tumor tissue is overexpressing PARP1, whereas healthy brain tissue has very low levels of the enzyme. This drastic difference in expression levels was also observed in human tissue [19] and led us to believe that a non-invasive imaging agent for PARP1 could be used to detect glioblastoma with high signal/noise ratios.

The goal of this project was therefore to develop a non-invasive PET-based imaging platform for PARP1. Based on our successful optical PARP1 imaging agents, we chose a $2 \mathrm{H}$-phthalazin-1-one scaffold [22] previously used by us for targeting glioblastoma cells [23]. We describe the synthesis of a targeted PARP1 tracer, which was labeled with the radioisotopes ${ }^{131} \mathrm{I}$ and ${ }^{124} \mathrm{I}$ (for SPECT and PET imaging, respectively). Specifically, we show the design of small molecular targeted agents and their validation in biochemical assays, both in cells and in vivo. We further use one tracer for ${ }^{131} \mathrm{I} /{ }^{124} \mathrm{I}$ SPECT and PET imaging of PARP1 in subcutaneous and orthotopic mouse models of cancer, thereby illustrating that the expression of PARP1 is highly upregulated and that our labeled tracer accumulates inside the nuclei of glioblastoma cells, where PARP1 is expressed.

\section{Methods}

Unless otherwise noted, all reagents were purchased from Sigma-Aldrich (St. Louis, MO) and used without further purification. $N$-succinimidyl-4-(tributylstannyl) benzoate was purchased from Synthonix (Cambridge, UK), 3-(3iodophenyl)propionic acid and 3-(4-iodophenyl)propionic acid from Matrix Scientific (Columbia, SC), and 4iodophenyl acetic acid from Alfa Aesar (Cambridge, UK). Olaparib (AZD2281) was purchased from LC Laboratories (Woburn, MA). 4-(4-Fluoro-3-(piperazine-1carbonyl)benzyl)phthalazin-1 $(2 \mathrm{H})$-one was synthesized as described previously [22]. ${ }^{1} \mathrm{H}$-nuclear MR (NMR) spectra were recorded at room temperature on a Bruker Avance 500 instrument operating at the frequency of $500 \mathrm{MHz}$ (Billerica, MA) and internally referenced to the residual solvent peaks, $\mathrm{CDCl}_{3}(7.26 \mathrm{ppm})$ or dimethyl sulfoxide (DMSO) $-\mathrm{d}_{6}(2.49 \mathrm{ppm})$. Mass spectroscopy data was recorded on a Waters Acquity Ultra Performance LC (Milford, MA). High-resolution mass data was recorded on a Waters LCT Premier XE mass spectrometer. Highperformance liquid chromatography (HPLC) and radioHPLC was performed on a Shimadzu HPLC system equipped with 2LC-10AT pumps and an SPD-M10AVP photodiode array detector (Columbia, MD). Radio-HPLC was performed using an identical Shimadzu system, additionally equipped with a Lablogic Scan-RAM RadioTLC/HPLC detector (Brandon, FL). Analytic runs were performed on a C18 Waters Atlantis T3 column $(6 \times$ $250 \mathrm{~mm}, 5 \mathrm{~mm})$. The solvent system included water (solvent A) and acetonitrile (AcN) (solvent B) for the purification and quality control of the radiotracers with a gradient of 5-95\% B between 0 and $15 \mathrm{~min}$ and $100 \%$ B between 15 and $25 \mathrm{~min}$. For the purification of non-radioactive precursors, water $(0.1 \%$ trifluoroacetic acid, solvent A) and acetonitrile (AcN) (0.1\% trifluoroacetic acid, solvent $\mathrm{B}$ ) were used, all with a flow rate of $1 \mathrm{~mL} / \mathrm{min}$ and a gradient of $5-95 \%$ B between 0 and 15 min, $95 \%$ B between 15 and 17 min, and 95-5 \% B between 17 and $18 \mathrm{~min}$.

\section{Synthesis of PARP1 inhibitors \\ 4-(4-fluoro-3-(4-(3-iodobenzoyl)piperazine-1- carbonyl)benzyl)phthalazin-1(2H)-one (I1-PARPi)}

To a solution of 4-(4-Fluoro-3-(piperazine-1-carbonyl)benzyl)phthalazin-1(2H)-one (10 mg, $0.0275 \mathrm{mmol})$, triethylamine $(40 \mu \mathrm{L}, 0.3 \mathrm{mmol})$ and HBTU $(16 \mathrm{mg}, 0.0413 \mathrm{mmol})$ in dimethyl formamide (DMF, $500 \mu \mathrm{L}$ ) were added to 3iodobenzoic acid $(6 \mathrm{mg}, 0.0275 \mathrm{mmol})$. The mixture was stirred at room temperature for $20 \mathrm{~h}$. The crude product was then purified by preparative HPLC and dried under vacuum, yielding a white solid (6.9 mg, $48 \%$ yield). ${ }^{1} \mathrm{H}-\mathrm{NMR}\left(\mathrm{CDCl}_{3}\right) \delta=10.00(\mathrm{~s}, 1 \mathrm{H}), 8.40-8.38(\mathrm{~m}, 1 \mathrm{H})$, 7.71-7.69 (m, 4H), 7.64-7.63 (m, 1H), 7.30-7.26 (m, $3 \mathrm{H}), 7.09(\mathrm{~m}, 1 \mathrm{H}), 7.04-6.87(\mathrm{~m}, 1 \mathrm{H}), 4.21(\mathrm{~s}, 2 \mathrm{H})$, 
3.71-3.29 (m, 8H). LC-ESI-MS (+) m/z $=597.1\left[\mathrm{M}+\mathrm{H}^{+}\right]^{+}$. HRMS-ESI $\left[\mathrm{M}-\mathrm{H}^{+}\right]^{-} \mathrm{m} / \mathrm{z}$ calculated for $\left[\mathrm{C}_{27} \mathrm{H}_{22} \mathrm{FIN}_{4} \mathrm{O}_{3}\right]^{-}$ 595.0642, found 595.0660.

\section{4-(4-fluoro-3-(4-(4-iodobenzoyl)piperazine-1- carbonyl)benzyl)phthalazin-1(2H)-one (I2-PARPi)}

A solution of 4-(4-fluoro-3-(piperazine-1-carbonyl)benzyl)phthalazin-1(2H)-one (10 mg, $0.0275 \mathrm{mmol})$, HBTU (16 mg, $0.0413 \mathrm{mmol})$, triethylamine $(40 \mu \mathrm{L}, 0.3 \mathrm{mmol})$, and 4-iodobenzoic acid (6 $\mathrm{mg}, 0.0245 \mathrm{mmol}$ ) in DMF $(500 \mu \mathrm{L})$ was stirred overnight at room temperature. The crude product was purified by preparative HPLC and dried under vacuum, yielding a white solid $(8.8 \mathrm{mg}$, $61 \%$ yield). ${ }^{1} \mathrm{H}-\mathrm{NMR}\left(\mathrm{CDCl}_{3}\right) \delta=10.48(\mathrm{~s}, 1 \mathrm{H}), 8.40-$ $8.39(\mathrm{~m}, 1 \mathrm{H}), 7.74-7.66(\mathrm{~m}, 5 \mathrm{H}), 7.27-7.26(\mathrm{~d}, 2 \mathrm{H}), 7.09-$ $7.07(\mathrm{~d}, 2 \mathrm{H}), 4.22(\mathrm{~s}, 2 \mathrm{H}), 3.73-3.14(\mathrm{~m}, 8 \mathrm{H})$. LC-ESI-MS $(+) \mathrm{m} / \mathrm{z}=597.1\left[\mathrm{M}+\mathrm{H}^{+}\right]^{+}$. HRMS-ESI $\left[\mathrm{M}-\mathrm{H}^{+}\right]^{-} \mathrm{m} / \mathrm{z}$ calculated for $\left[\mathrm{C}_{27} \mathrm{H}_{22} \mathrm{FIN}_{4} \mathrm{O}_{3}\right]^{-}$595.0642, found 595.0640.

\section{4-(4-fluoro-3-(4-(2-(3-iodophenyl)acetyl)piperazine-1- carbonyl)benzyl)phthalazin-1(2H)-one (I3-PARPi)}

A solution of 3-iodophenyl acetic acid $(6.5 \mathrm{mg}$, $0.048 \mathrm{mmol}$ ), 1-ethyl-3-(3-dimethylaminopropyl) carbodiimide (EDC) (10.5 mg, $0.055 \mathrm{mmol}$ ), $\mathrm{N}$-hydroxy succinimide (NHS), and $600 \mu \mathrm{L}$ DMF was stirred for $30 \mathrm{~min}$ at room temperature. Then, 4-(4-fluoro-3-(piperazine-1-carbonyl)benzyl)phthalazin-1(2H)-one (10 mg, $0.0275 \mathrm{mmol})$ was added to the solution, and the mixture was stirred at room temperature overnight. The reaction was washed with $500 \mu \mathrm{L}$ of $\mathrm{H}_{2} \mathrm{O}$ and extracted with $500 \mu \mathrm{L}$ dichloromethane (DCM). The resulting organic solution was purified on silica gel, using a gradient elution from neat DCM to DCM/hexane 5:1 to obtain the desired product as a white solid ( $3 \mathrm{mg}, 20 \%$ yield). ${ }^{1} \mathrm{H}-\mathrm{NMR}\left(\mathrm{CDCl}_{3}\right) \delta=9,82(\mathrm{~s}, 1 \mathrm{H}), 8.40-8.38(\mathrm{~m}, 1 \mathrm{H})$, 7.71-7.69 (m, 2H), 7.55-7.53 (m, 1H), 7.51-7.50 (m, 2H), 7.25-7.24 (m, 2H), 7.09-6.90 (m, 3H), $4.20(\mathrm{~s}, 2 \mathrm{H})$, 3.64-3.31 (m, 8H), 2.84 (s, 2H). LC-ESI-MS $(+) \mathrm{m} / \mathrm{z}=$ $633.1\left[\mathrm{M}+\mathrm{Na}^{+}\right]^{+}$. HRMS-ESI $\left[\mathrm{M}+\mathrm{H}^{+}\right]^{+} \mathrm{m} / \mathrm{z}$ calculated for $\left[\mathrm{C}_{28} \mathrm{H}_{24} \mathrm{FIN}_{4} \mathrm{O}_{3}\right]^{+}$611.0955, found 611.0948.

\section{4-(4-fluoro-3-(4-(2-(4-iodophenyl)acetyl)piperazine-1- carbonyl)benzyl)phthalazin-1(2H)-one (I4-PARPi)}

A solution of 4-iodophenyl acetic acid $(6.5 \mathrm{mg}$, $0.048 \mathrm{mmol})$, EDC $(10.5 \mathrm{mg}, 0.055 \mathrm{mmol}), \mathrm{NHS}$, and $600 \mu \mathrm{L}$ DMF was stirred for $30 \mathrm{~min}$ at room temperature. After this time, the 4-(4-fluoro-3-(piperazine-1-carbonyl)benzyl)phthalazin- $1(2 \mathrm{H})$-one $(10 \mathrm{mg}, 0.0275 \mathrm{mmol})$ was added to the solution and the mixture was stirred at room temperature overnight. $\mathrm{H}_{2} \mathrm{O}(500 \mu \mathrm{L})$ was added, the mixture was extracted with DCM $(2 \times 500 \mu \mathrm{L})$, and the combined extracts were dried under vacuum. The crude mixture was purified by silica column chromatography (100\% DCM), and the product obtained was a white solid $(8.8 \mathrm{mg}, 61 \%) .{ }^{1} \mathrm{H}-\mathrm{NMR}\left(\mathrm{CDCl}_{3}\right) \delta=9.82(\mathrm{~s}, 1 \mathrm{H})$, 8.40-8.38 (m, 1H), 7.83-7.81 (d, $1 \mathrm{H}), 7.77-7.75(\mathrm{~d}, 1 \mathrm{H})$, 7.70-7.69 (m, 2H), 7.63-7.56 (m, 3H), 7.00-6.89 (m, 3H), $4.20(\mathrm{~s}, 2 \mathrm{H}), 3.63-3.11(\mathrm{~m}, 8 \mathrm{H}), 2.84(\mathrm{~s}, 2 \mathrm{H})$. LC-ESI-MS (+) $\mathrm{m} / \mathrm{z}=632.9\left[\mathrm{M}+\mathrm{Na}^{+}\right]^{+}$. HRMS-ESI $\left[\mathrm{M}+\mathrm{H}^{+}\right]^{+} \mathrm{m} / \mathrm{z}$ calculated for $\left[\mathrm{C}_{28} \mathrm{H}_{24} \mathrm{FIN}_{4} \mathrm{O}_{3}\right]^{+}$611.0955, found 611.0971.

\section{4-(4-fluoro-3-(4-(3-(3-iodophenyl)propanoyl)piperazine-1- carbonyl)benzyl)phthalazin-1(2H)-one (I5-PARPi)}

A solution of 4-(4-fluoro-3-(piperazine-1-carbonyl)benzyl)phthalazin-1(2H)-one (10 mg, $0.0275 \mathrm{mmol})$, HBTU (16 mg, $0.0413 \mathrm{mmol})$, triethylamine $(40 \mu \mathrm{L}, 0.3 \mathrm{mmol})$, and 3-(3-iodophenyl)propionic acid (7.6 $\mathrm{mg}, 0.0275 \mathrm{mmol}$ ) in $400 \mu \mathrm{L}$ of $\mathrm{AcN}$ was stirred overnight at room temperature. The crude product was then purified by preparative HPLC and the isolated product dried at vacuum to obtain a white solid (5.1 mg, $38 \%) .{ }^{1} \mathrm{H}-\mathrm{NMR}\left(\mathrm{CDCl}_{3}\right)$ $\delta=10.33(\mathrm{~s}, 1 \mathrm{H}), 8.41-8.39(\mathrm{~d}, 1 \mathrm{H}), 7.71-7.63(\mathrm{~m}, 3 \mathrm{H})$, 7.51-7.45 (m, 2H), 7.27-7.25 (m, 2H), 7.12-6.92 (m, 3H), $4.22(\mathrm{~s}, 2 \mathrm{H}), 3.65-3.12(\mathrm{~m}, 8 \mathrm{H}), 2.88-2.83(\mathrm{~m}, 2 \mathrm{H}), 2.59-$ $2.48(\mathrm{~m}, 2 \mathrm{H})$. LC-ESI-MS (+) $\mathrm{m} / \mathrm{z}=647.1\left[\mathrm{M}+\mathrm{Na}^{+}\right]^{+}$. HRMS-ESI $\left[\mathrm{M}+\mathrm{H}^{+}\right]^{+} \mathrm{m} / \mathrm{z}$ calculated for $\left[\mathrm{C}_{29} \mathrm{H}_{26} \mathrm{FIN}_{4} \mathrm{O}_{3}\right]^{+}$ 625.1112, found 625.1111.

\section{4-(4-fluoro-3-(4-(3-(4-iodophenyl)propanoyl)piperazine-1- carbonyl)benzyl) phthalazin-1(2H)-one (I6-PARPi)}

4-(4-Fluoro-3-(piperazine-1-carbonyl)benzyl)phthalazin$1(2 \mathrm{H})$-one $(10 \mathrm{mg}, 0.0275 \mathrm{mmol})$ was mixed with HBTU (16 mg, $0.0413 \mathrm{mmol})$, triethylamine $(40 \mu \mathrm{L}$, $0.3 \mathrm{mmol}$ ), and 4-iodo-3-phenyl propionic acid $(7.6 \mathrm{mg}$, $0.0275 \mathrm{mmol}$ ) in $400 \mu \mathrm{L}$ of $\mathrm{AcN}$, and the solution was stirred overnight at room temperature. The crude product was then purified by preparative HPLC and the isolated product dried at vacuum to obtain a white solid $(7.5 \mathrm{mg}$, $45 \%) .{ }^{1} \mathrm{H}-\mathrm{NMR}\left(\mathrm{CDCl}_{3}\right) \delta=9.71(\mathrm{~s}, 1 \mathrm{H}), 8.40-8.38(\mathrm{~d}$, $1 \mathrm{H}), 7.70-7.69(\mathrm{~m}, 2 \mathrm{H}), 7.64-7.63(\mathrm{~m}, 1 \mathrm{H}), 7.55-7.52$ (m, 2H), 7.27-7.25 (m, 2H), 7.00-6.97 (m, 1H), 6.91$6.87(\mathrm{~m}, 2 \mathrm{H}), 4.20(\mathrm{~s}, 2 \mathrm{H}), 3.64-3.11(\mathrm{~m}, 8 \mathrm{H}), 2.87-2.85$ $(\mathrm{m}, 2 \mathrm{H}), 2.63-2.47(\mathrm{~m}, 2 \mathrm{H})$. LC-ESI-MS $(+) \mathrm{m} / \mathrm{z}=$ $647.1\left[\mathrm{M}+\mathrm{Na}^{+}\right]^{+}$. HRMS-ESI $\left[\mathrm{M}+\mathrm{Na}^{+}\right]^{+} \mathrm{m} / \mathrm{z}$ calculated for $\left[\mathrm{C}_{29} \mathrm{H}_{26} \mathrm{FIN}_{4} \mathrm{O}_{3} \mathrm{Na}\right]^{+}$647.0931, found 647.0941.

\section{Radiochemistry}

$\left[{ }^{131} \mathrm{I}\right]-\mathrm{NaI}$ was purchased at Nordion (Ottawa, ON, Canada) in $\mathrm{NaOH}$ solution $(0.1 \mathrm{M})$ with a concentration of $0.99-2.5 \mathrm{mCi} / \mu \mathrm{L}$. [ $\left.{ }^{124} \mathrm{I}\right]-\mathrm{NaI}$ was produced at Memorial Sloan-Kettering Cancer Center (New York, NY) in $\mathrm{NaOH}$ solution $(0.5 \mathrm{M})$ with a concentration of $0.20-0.40 \mathrm{mCi} / \mu \mathrm{L}$.

\section{Synthesis of $\left.{ }^{131} I\right]-N H S-b e n z o a t e$}

Precursor $N$-succinimidyl-4-(tributylstannyl) benzoate (30 $\mu \mathrm{g}, 5.9 \mathrm{nmol}$ ) was dissolved in $30 \mu \mathrm{L}$ of $\mathrm{AcN}$, and the solution was added to a solution of methanol $(40 \mu \mathrm{L})$, chloramine $\mathrm{T}(6 \mu \mathrm{g}, 0.03 \mathrm{nmol})$ in acetic acid 
$(2 \mu \mathrm{L})$, and $\left[{ }^{131} \mathrm{I}\right]-\mathrm{NaI}$ in $\mathrm{NaOH} 0.1 \mathrm{M}(1-2.5 \mathrm{mCi})$. After $5 \mathrm{~min}$ at room temperature, the reaction was purified by HLPC on a C18 Waters Atlantis T3 column (6x $250 \mathrm{~mm}, 5 \mathrm{~mm}$ ), using water (solvent A) and AcN (solvent B) as mobile phase, with an elution gradient from 5 to $100 \%$ for solvent B over $15 \mathrm{~min}$ and then $100 \%$ of solvent B from 15 to $25 \mathrm{~min}$. The retention time of [ $\left.{ }^{131} \mathrm{I}\right]$ NHS benzoate was $14.3 \mathrm{~min}$, and its identity was established by co-elution with the reference cold compound. The radiochemical yield was $67 \pm 6 \%(n=12)$, and the radiochemical purity was $>98 \%$. The collected fraction containing $\left[{ }^{131} \mathrm{I}\right]-\mathrm{NHS}$ benzoate was concentrated to dryness under vacuum.

The same procedure was followed for the synthesis of $\left[{ }^{124} \mathrm{I}\right]-\mathrm{NHS}$ benzoate. In this case, the radiochemical yield was $32 \pm 5 \%(n=5)$ and the purity was $>95 \%$.

\section{Synthesis of $\left[{ }^{131} I\right]-12-P A R P i$}

The dried radiolabeled $\left[{ }^{131} \mathrm{I}\right]$-NHS-benzoate precursor was dissolved in $200 \mu \mathrm{L}$ of AcN, and an excess of HBTU (1 mg, $2.6 \mathrm{nmol}$ ) and 4-(4-fluoro-3-(piperazine-1-carbonyl)benzyl)phthalazin-1(2H)-one $(1 \mathrm{mg}, 2.7 \mathrm{nmol})$ was added and allowed to react for $3 \mathrm{~h}$ at $32{ }^{\circ} \mathrm{C}$. The final product was purified by HPLC, using water (solvent A) and $\mathrm{AcN}$ (solvent $\mathrm{B}$ ) as solvents with a gradient elution from 5 to $100 \%$ of solvent B over $15 \mathrm{~min}$ and then $100 \%$ of B from 15 to $25 \mathrm{~min}$. The retention time of $\left[{ }^{131} \mathrm{I}\right]$-I2-PARPi was $13.1 \mathrm{~min}$, and its identity was established by co-elution with the reference cold compound. The radiochemical yield was $72 \pm 8 \%(n=12)$ and the radiochemical purity $>95 \%$. The collected fraction containing $\left[{ }^{131} \mathrm{I}\right]-\mathrm{I} 2-\mathrm{PARPi}$ was concentrated to dryness under reduced pressure.

The same procedure was followed for the synthesis of $\left[{ }^{124} \mathrm{I}\right]-\mathrm{I} 2-\mathrm{PARPi}$. In this case, the radiochemical yield was $68 \pm 5 \%(n=5)$ and the purity $>95 \%$.

\section{Cell culture}

The human glioblastoma cell lines U251 MG and U87 MG were generously provided by the Laboratory of Dr. Ronald Blasberg (MSKCC, New York, NY). All cell lines were grown in Eagle's minimal essential medium (MEM) containing $10 \%(v / v)$ heat-inactivated fetal bovine serum, $100 \mathrm{IU}$ penicillin, and $100 \mu \mathrm{g} / \mathrm{mL}$ streptomycin. Cells were cultured at $37{ }^{\circ} \mathrm{C}$ in a humidified $5 \% \mathrm{CO}_{2}$ atmosphere. All media was purchased from the media preparation facility at MSKCC (New York, NY).

\section{Mouse models}

Six 10-week-old female athymic nude CrTac:NCr-Fo mice from Taconic Laboratories (Hudson, NY) were used for all mouse experiments. During subcutaneous injections, mice were anesthetized using $2 \%$ isoflurane gas in $2 \mathrm{~L} / \mathrm{min}$ medical air. During orthotopic injections, mice were anesthetized using a $150 \mathrm{mg} / \mathrm{kg}$ ketamine and $15 \mathrm{mg} / \mathrm{kg}$ xylazine cocktail $(10 \mu \mathrm{L} / \mathrm{g})$. Before all intravenous injections, mice were gently warmed with a heat lamp and placed in a restrainer and tails were sterilized with alcohol pads. The lateral tail vein was used for all intravenous injections. All mouse experiments were done in accordance with protocols approved by the Institutional Animal Care and Use Committee of MSKCC and followed National Institutes of Health (NIH) guidelines for animal welfare.

\section{PARP-1 $1 \mathrm{IC}_{50}$ determination}

A commercially available colorimetric assay (Trevigen, Gaithersburg, MD) was used to measure PARP-1 activity in vitro in the presence of varying concentrations of the different iodo-PARPis. Specifically, dilutions of iodoPARPi (final concentrations ranging from $3.3 \mu \mathrm{M}$ to 0.1 $\mathrm{nM}$ ) were incubated with $0.5 \mathrm{U}$ of PARP1 high specific activity (HSA) enzyme for $10 \mathrm{~min}$ in histone-coated 96well plates. All experiments were carried out in triplicate. Positive control samples did not contain inhibitor, and negative control samples did not contain PARP1. All reaction mixtures were adjusted to a final volume of $50 \mu \mathrm{l}$, and a final concentration of $1 \%$ DMSO in assay buffer. The remainder of the assay was performed according to the manufacturer's instructions. PARP1 activity was measured by absorbance at $450 \mathrm{~nm}$ in each well using a SpectraMax M5 spectrophotometer with SoftMax Pro software (Molecular Devices, Sunnyvale, CA).

\section{Hydrophobicity index determination}

Chemical hydrophobicity indices (CHIs) were measured using procedures developed previously [24]. Briefly, reverse phase HPLC was used to measure the retention times of a set of standards with known CHI. A standard curve was then created to calculate the CHIs of all iodoPARPi based on the HPLC retention time. Log $P$ values were derived from $\mathrm{CHI}$ values following the equation: $\log P=0.0566 \pm \mathrm{CHI}-1.107$.

\section{Plasma protein fraction}

The plasma protein fraction was determined using the Rapid Equilibrium Dialysis Device System (Life Technologies, Grand Island, NY) according to the manufacturer's protocol. Membrane dialysis was performed with $10 \mu \mathrm{M}$ of compound in mouse serum $(500 \mu \mathrm{L})$ on one side of the membrane and PBS $(750 \mu \mathrm{L})$ on the other side. The system was sealed with parafilm and incubated for $4 \mathrm{~h}$ at $37{ }^{\circ} \mathrm{C}$ on an orbital shaker set to $250 \mathrm{rpm}$. Thereafter, $400 \mu \mathrm{L}$ of solution was taken from both sides, and samples were treated twice with an equal amount of AcN and vortexed to remove protein before HPLC analysis. After injection $(100 \mu \mathrm{L})$, the I-PARPi peaks from each sample were then integrated and the 
protein bound fraction was determined. The data was analyzed using Prism 6.0c.

\section{Immunohistochemistry \\ PARP1 expression in tissues}

PARP1 antigen detection in glioblastoma xenografts and mouse brain was performed at MSKCC's Molecular Cytology Core Facility using the Discovery XT processor (Ventana Medical Systems, Tucson, AZ) and detected using immunofluorescence (IF) staining. Paraffin-embedded formalin-fixed $3 \mu \mathrm{m}$ sections were deparaffinized with EZPrep buffer, antigen retrieval was performed with CC1 buffer (both Ventana Medical Systems), and sections were blocked for 30 min with Background Buster solution (Innovex, Richmond, CA). Anti-PARP1 rabbit polyclonal antibody (sc-7150, $0.2 \mu \mathrm{g} / \mathrm{mL}$; Santa Cruz Biotechnology, Santa, Cruz, CA) was incubated for $5 \mathrm{~h}$, followed by $1 \mathrm{~h}$ incubation with biotinylated goat antirabbit IgG (Vector labs, PK6106) at a 1:200 dilution. Detection was performed with Streptavidin-HRP D (from DABMap Kit, Ventana Medical Systems), followed by incubation with Tyramide Alexa Fluor 594. (T20935; Invitrogen, Carlsbad, CA) prepared according to the manufacturer's instructions. Sections were counterstained with 4',6-diamidino-2-phenylindole (DAPI) and coverslipped with $\mathrm{Mowiol}^{\circ}$ mounting medium (Sigma-Aldrich, St. Louis, MO). H\&E staining was performed on adjacent sections for morphological evaluation of tissue characteristics.

\section{Quantification of PARP1 expression}

Protein expression was quantified on digitalized PARP1stained sections using at least ten fields of view per section. Thresholding of the blue (nuclei stained with DAPI) and red fluorescent area (nuclei stained with PARP1) was performed using MetaMorph ${ }^{\circ}$ Software (Molecular Devices, Sunnyvale, CA). PARP1 intensity was determined by measuring the red fluorescence intensity in the area of all nuclei, and the \% PARP1 positive nuclear area was calculated by dividing the PARP1 positive area by the DAPI positive area in each field of view.

\section{In vitro blocking study}

U87 MG cells were seeded into a 96-well plate in a concentration of $1 \times 10^{4}$ cells per well. After $24 \mathrm{~h}$, the cells were incubated with either the fluorescent PARP1 inhibitor PARPi-FL $(250 \mathrm{nM})$ alone or with one of the iodo-PARPi inhibitors at a 100-fold higher concentration $(25 \mu \mathrm{M})$ for $20 \mathrm{~min}$. Additionally, as a positive control, the PARP1 inhibitor Olaparib was used. All incubation solutions also included Hoechst 33342 nuclear stain (Sigma-Aldrich, St. Louis, MO). The cells were washed twice with media and once with PBS for 5 min each and imaged on an LSM 5Live confocal microscope (Zeiss, Oberkochen, Germany). All wells were imaged with the
DAPI filter for the Hoechst staining and the FITC filter for the PARPi-FL staining. The DAPI and FITC channels were co-registered, and the green fluorescence in the location of the Hoechst staining was quantified for each image. The percent reduction in PARPi-FL uptake was calculated based on the level of fluorescence intensity seen in each image and normalized to the cells receiving no iodo-PARPi inhibitor. Experiments were performed in triplicate.

\section{Blood half-life}

Blood half-life was determined by measuring the activity in serial blood samplings. Specifically, healthy female nude mice (8-10 weeks old, 20-25 g in weight, $n=3$ ) were injected via the tail vein with $50 \mu \mathrm{Ci}\left[{ }^{131} \mathrm{I}\right]-\mathrm{I} 2$ PARPi in $200 \mu \mathrm{L}$ of solution PBS/PEG 300 (10:1). The blood was sampled from the saphenous vein at $5,15,30$, 60,120 , and $240 \mathrm{~min}$ post injection. The blood was weighed and radioactivity was measured on a Wizard 2470 Automatic Gamma Counter (Perkin Elmer, Waltham, MA). Measurements in counts per minute were calculated as the mean \%ID/g. The blood half-life was calculated using Prism 6.0c (GraphPad Software, La Jolla, CA).

\section{In vivo blocking study}

To verify the specificity of tumor uptake of I2-PARPi in vivo, the level of blocking of the fluorescent PARP1 inhibitor on a macroscopic and microscopic scale was determined. Nude mice bearing subcutaneous U87 MG tumors were injected with either the fluorescent PARP1 inhibitor PARPi-FL alone $(2.5 \mathrm{mg} / \mathrm{kg}, 200 \mu \mathrm{L}$ of $19.5 \%$ 1:1 DMAC:Kolliphor, 3.5 \% DMSO, 77 \% PBS), PARPiFL 30 min after a pre-injection of a 50-fold excess of I2PARPi $\left(125 \mathrm{mg} / \mathrm{kg}, 100 \mu \mathrm{L}\right.$ of $\left.10 \% \mathrm{PEG}_{300}, 90 \% \mathrm{PBS}\right)$, or injected with saline alone. One hour post injection, the mice were sacrificed and the tumors were resected and imaged with the IVIS spectrum fluorescence imaging system (PerkinElmer, Waltham, MA) using Living Image 4.4 software. The tumors were also imaged microscopically with the 5 Live fluorescent confocal microscope using the $488 \mathrm{~nm}$ laser for PARPi-FL excitation.

\section{In vitro whole blood stability}

The in vitro stability was assessed by incubating $6 \mu \mathrm{Ci}$ $\left[{ }^{131} \mathrm{I}\right]$-PARPi in mouse blood for 0 to $60 \mathrm{~min}$ at $37^{\circ} \mathrm{C}$. At baseline, 15, 30, and $60 \mathrm{~min}$, the samples were immediately placed on ice and mixed 1:1 with a solution of AcN/DMSO $(250 \mu \mathrm{L})$ and then vigorously vortexed for $30 \mathrm{~s}$ to precipitate out serum protein. The sample was centrifuged at $3000 \mathrm{RCF}$ for $3 \mathrm{~min}$ at $4{ }^{\circ} \mathrm{C}$, and the supernatant was collected. This procedure was repeated three times, and the combined supernatants were analyzed by HPLC equipped with radioactive detector (Shimadzu, Kyoto, Japan), collecting samples every $30 \mathrm{~s}$. 
Radioactivity of each fraction was measured on a Wizard 2470 Automatic Gamma Counter (Perkin Elmer, Waltham, MA), and the blood stability was analyzed using Prism 6.0c (GraphPad Software, La Jolla, CA).

\section{Biodistribution studies}

Biodistribution experiments were conducted on female nude mice (8-10 weeks old and $20-25 \mathrm{~g}$ in weight, $n=21$ ) bearing U87 MG or U251 MG subcutaneous xenografts. The radiolabeled small molecule preparation $\left(30-20 \mu \mathrm{Ci}\right.$ of $\left[{ }^{131} \mathrm{I}\right]-\mathrm{I} 2-\mathrm{PARPi}$ in $200 \mu \mathrm{L}$ of a solution $90 \%$ PBS $10 \%$ PEG $_{300}$ ) was administrated via the lateral tail vein. To determine the optimal specific activity to achieve the highest tumor to organ ratio, various specific activities were tested $(5,50$, and $250 \mathrm{mCi} / \mu \mathrm{mol})$ in mice bearing U87 MG tumors. The compound was allowed to circulate for $2 \mathrm{~h}$ post injection at which time the mice were sacrificed and organs were harvested $(n=3)$. After determining the optimal specific activity, the optimal time for imaging was determined by testing the drug distribution in nude mice bearing U87 MG tumors at different time points. The drug was allowed to circulate for various times $(1,2$, and $6 \mathrm{~h})$, after which the mice were sacrificed $(n=3)$. The radioactive content in the tissue of interest (blood, tumor, muscle, bone, liver, spleen, kidney, heart, lung, pancreas, brain, skin, small intestine, large intestine, stomach, tail, thyroid, and feces) was measured on a Wizard 2470 Automatic Gamma Counter and the tissueassociated activity was calculated as the mean $\% \mathrm{ID} / \mathrm{g}$.

\section{Autoradiography}

U251 MG glioblastoma cells $\left(5 \times 10^{4}\right.$ in $2 \mu \mathrm{L}$ of PBS $)$ were orthotopically implanted in athymic nude mice, using a stereotaxic device, and the tumors were allowed to grow for approximately 4 weeks. Once tumors reached the sufficient size, the orthotopic U251 MG tumor-bearing mice were injected intravenously with $500 \mu \mathrm{Ci}\left[{ }^{131} \mathrm{I}\right]$-PARPi (in $200 \mu \mathrm{L}$ of a solution PBS $90 \%$ $\mathrm{PEG}_{300} 10 \%, n=2$ ) alone or with a pre-injection of $15 \mu \mathrm{mol}$ Olaparib (in $100 \mu \mathrm{L}$ of $7.5 \%$ DMSO, $12.5 \%$ $\left.\mathrm{PEG}_{300}, 80 \% \mathrm{PBS}\right) 30 \mathrm{~min}$ prior to the injection of $\left[{ }^{131} \mathrm{I}\right]$-PARPi. Additionally, healthy mice were also injected with $500 \mu \mathrm{Ci}\left[{ }^{131} \mathrm{I}\right]$-PARPi. After $2 \mathrm{~h}$ of circulation time after the $\left[{ }^{131} \mathrm{I}\right]$-PARPi injection, the mice were sacrificed. Liver, tumor, muscle, and brain tissues were excised and embedded in O.C.T. compound (Sakura Finetek, Torrance, CA) and frozen at $-20{ }^{\circ} \mathrm{C}$, and a series of $8 \mu \mathrm{m}$ frozen sections was cut and mounted on microscope slides. To determine radiotracer distribution, digital autoradiography was performed by placing tissue sections in a film cassette against a phosphor image plate (BASMS-2325; Fujifilm) for $48 \mathrm{~h}$ at $-20^{\circ} \mathrm{C}$. Phosphor imaging plates were read at a pixel resolution of $25 \mu \mathrm{m}$ with a Typhoon 7000IP plate reader (GE Healthcare, Piscataway,
$\mathrm{NJ})$. After autoradiographic exposure, the same frozen sections were then used for immunohistochemical staining. Areas of brain slides containing tumor tissue were identified using the H\&E staining and then overlaid with the autoradiographic data. Intensity of tumor areas and nontumor areas were then quantified using ImageJ $1.47 \mathrm{u}$.

\section{In vivo imaging}

SPECT/CT was acquired in athymic nude mice (6-10 weeks old). Before administration of the radioiodinated tracer, in terms to block the thyroid, the animals were treated with an intraperitoneal injection of $\mathrm{NaI}(100 \mu \mathrm{L}$, $0.6 \mathrm{mM}) 60 \mathrm{~min}$ previous to the injection of 450 $600 \mu \mathrm{Ci}(145-210 \mathrm{mCi} / \mu \mathrm{mol})\left[{ }^{131} \mathrm{I}\right]-\mathrm{I} 2-\mathrm{PARPi}$ in $200 \mu \mathrm{L}$ PBS solution $\left(10 \% \mathrm{PEG}_{300}\right)$ via the lateral tail vein and then anesthetized with isoflurane mixed with medical air ( $2 \%$ for induction and maintenance). Animals were placed in prone position, and scans were then performed $90 \mathrm{~min}$ after injection for $60 \mathrm{~min}$ using a SPECT/CT small animal imaging system (NanoSPECT/CT, Mediso, Boston, MA). SPECT Images were reconstructed using HiSPECT software, and in vivo Scope software was used for CT image reconstruction.

In the case of PET imaging, images were acquired after the injection of $200-250 \mu \mathrm{Ci}(110-170 \mu \mathrm{mCi} / \mu \mathrm{mol})$ $\left[{ }^{124} \mathrm{I}\right]$-I2-PARPi in $200 \mu \mathrm{L}$ PBS solution $\left(10 \% \mathrm{PEG}_{300}\right)$ via the lateral tail vein under isoflurane anesthesia $(2 \%$ for induction and $1.5 \%$ for maintenance). Mice were also treated with an intraperitoneal injection of $\mathrm{NaI}$ $(100 \mu \mathrm{L}, 0.6 \mathrm{mM}), 60 \mathrm{~min}$ previous to the administration of the radioiodinated tracer. Animals were immediately placed in prone position under isoflurane anesthesia, and scans were then performed $90 \mathrm{~min}$ after injection for $30 \mathrm{~min}$ using the Inveon PET/CT imaging system (Siemens, Knoxville, TN). PET and CT Images were reconstructed using Inveon research workplace software.

\section{Formulation of $\left[{ }^{131} /{ }^{124} \mid\right]-$-12-PARPi for in vivo injection}

For in vivo applications, the radioactive ${ }^{124} \mathrm{I} /{ }^{131} \mathrm{I}-\mathrm{I} 2$ PARPi was injected intravenously, using hypodermic syringes with $200 \mu \mathrm{L}$ of a solution of PBS $1 \times$ and $\mathrm{PEG}_{300}$ $(9 / 1 v / v)$. We used approximately $450-600 \mu \mathrm{Ci}$ of radiotracer for PET imaging, 200-250 $\mu \mathrm{Ci}$ for SPECT imaging, $500 \mu \mathrm{Ci}$ for autoradiography, and $30-20 \mu \mathrm{Ci}$ for biodistributions.

\section{Results}

\section{Immunohistochemistry}

Immunofluorescence PARP1 antigen detection in histological sections of U251 MG and U87 MG glioblastoma xenografts showed an overexpression of PARP1 compared to healthy brain tissue (Fig. 1a). The PARP1 positive area in glioblastoma slides was increased by a factor of $15.8 \pm 8.1$ (Fig. 1b). The percent PARP1 positive area 

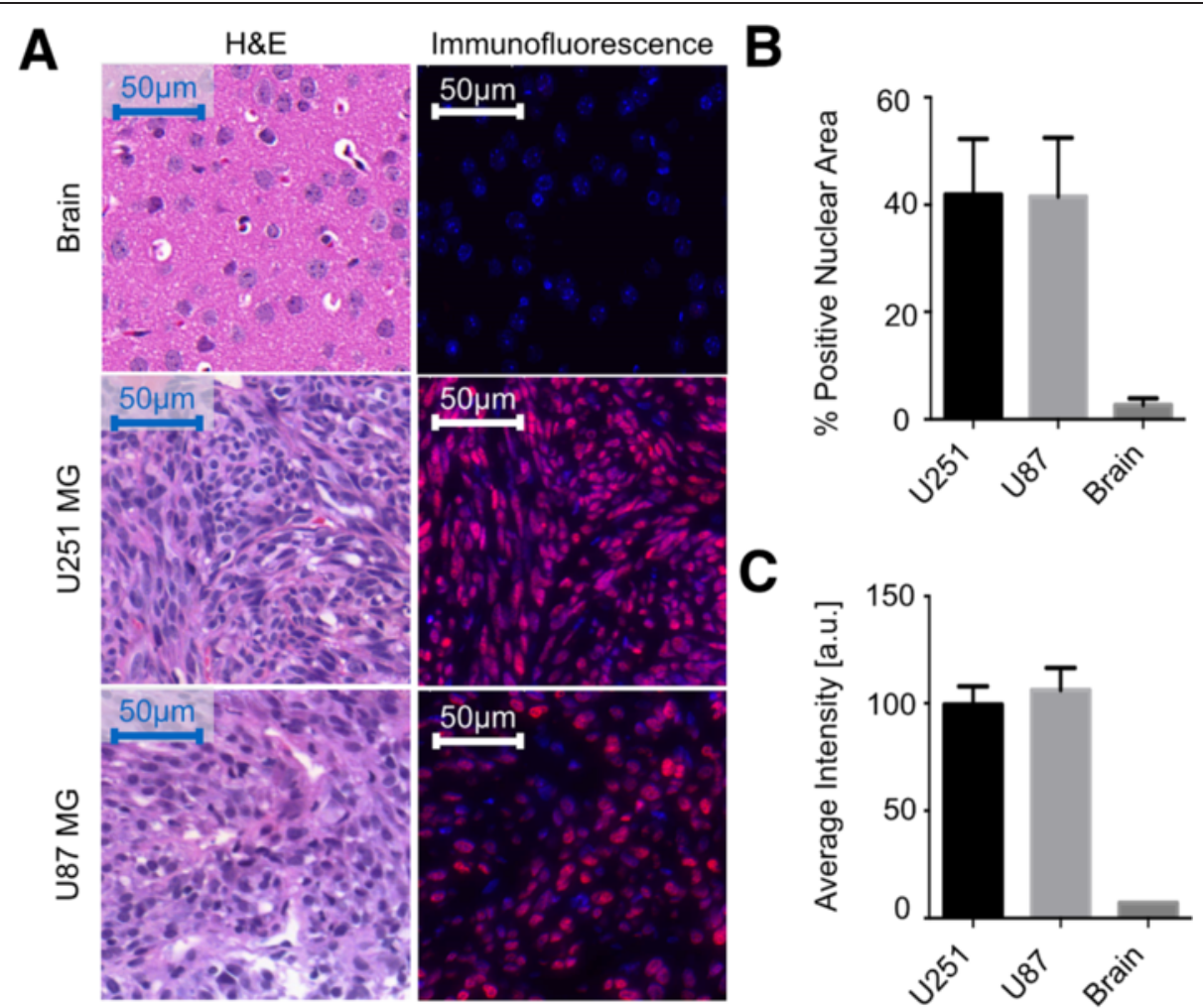

Fig. 1 PARP1 immunofluorescence staining of brain, U251 MG xenografts, and U87 MG xenografts. a Representative images showing H\&E staining (left) and PARP1 immunofluorescence staining (right) of each tissue type. $\mathbf{b}$ Percent of nuclei positive for PARP1 for each tissue type. $\mathbf{c}$ Average intensity of nuclei in each cell type

in both glioblastoma models was similar, with $42.0 \pm$ $10.4 \%$ and $41.5 \pm 11.0 \%$ for U251 MG and U87 MG, respectively (for healthy brain, PARP1 positive area was $2.7 \pm 1.3 \%)$. In the same way, glioblastoma tissues present similar values in average intensity $(99.5 \pm 8.5 \mathrm{AU}$ for U251 MG and 106.2 \pm 10.5 AU for U87 MG, Fig. 1c) with values over 14-fold higher than healthy tissue, confirming optimal target/background ratios for in vivo evaluation.

\section{Synthesis of iodinated PARP1 inhibitors}

The molecular structure of all iodinated PARP1 tracers is based on the $(2 \mathrm{H})$-phthalazin-1-one scaffold of the small molecule therapeutic Olaparib (Fig. 2a). The synthesis of a library of test compounds, consisting of six different inhibitors (Fig. 2), was carried out through the coupling of the PARP Inhibitor precursor 4-(4-fluoro-3(piperazine-1-carbonyl)benzyl)phthalazin-1(2H)-one and different iodinated carboxylic acids. The reaction was performed in the presence of HBTU and triethylamine or EDC and NHS at room temperature, overnight, and crude mixtures were purified by HPLC or silica column, resulting in the isolation of I1-PARPi through I6-PARPi in good yields (Fig. 2b, Additional file 1: Figures S2 and S3).
Pharmacokinetic properties of non-radioactive compounds

The obtained $\mathrm{IC}_{50}$ values of all the small molecules were in the nanomolar range $(9 \pm 2-107 \pm 4 \mathrm{nM})$. I1-PARPi and I2-PARPi showed the highest affinity (11 \pm 3 and $9 \pm 2 \mathrm{nM}$, respectively), with values close to Olaparib (5 nM, [22]). All inhibitors had a CHI between 59.6 and 71.6, which corresponds to $\log P_{\mathrm{CHI}}$ values between 2.3 and 3.0. These values were lower for Olaparib $(\mathrm{CHI}=$ 34.1, $\log _{\mathrm{CHI}}=0.8$ ) but adequate for crossing the bloodbrain barrier for application in brain diseases [2]. The iodinated molecules showed relatively high plasma protein binding, with the protein plasma free fraction ranging between 4.69 and $11.53 \%$ (Fig. 3).

\section{In vitro and in vivo competitive optical imaging}

To demonstrate the specific binding of our inhibitors to PARP1, in vitro competition assays were performed with the small molecules and their fluorescent sister imaging agent, PARPi-FL [25]. PARPi-FL alone led to strong nuclear fluorescence, where the agent was retained by PARP1. The reduction in fluorescent signal in the presence of all inhibitors confirmed their ability to diffuse into the nucleus of the cell and bind PARP1 (Fig. 4a). When PARPi-FL was added to cells that were co-treated 
A<smiles>O=C(c1cc(Cc2n[nH]c(=O)c3ccccc23)ccc1F)N1CCN(C(=O)C2CC2)CC1</smiles>

B<smiles>[R6]c1ccc(CCC(=O)N2CCN(C(=O)c3cc(Cc4n[nH]c(=O)c5ccccc45)ccc3F)CC2)cc1Br</smiles>

C

\begin{tabular}{|c|c|c|c|c|c|c|}
\hline & $\mathbf{n}$ & $\mathbf{R}_{1}$ & $\mathbf{R}_{\mathbf{2}}$ & Isomer & Yield & Coupling Conditions \\
\hline I1-PARPi & 0 & I & $\mathrm{H}$ & meta & $48 \%$ & HBTU/DMF/Et ${ }_{3} \mathrm{~N}$ \\
\hline I2-PARPi & 0 & $\mathrm{H}$ & 1 & para & $61 \%$ & $\mathrm{HBTU} / \mathrm{DMF} / \mathrm{Et}_{3} \mathrm{~N}$ \\
\hline I3-PARPi & 1 & 1 & $\mathrm{H}$ & meta & $20 \%$ & $\mathrm{HBTU} / \mathrm{DMF} / \mathrm{Et}_{3} \mathrm{~N}$ \\
\hline I4-PARPi & 1 & $\mathrm{H}$ & 1 & para & $29 \%$ & $\mathrm{HBTU} / \mathrm{DMF} / \mathrm{Et}_{3} \mathrm{~N}$ \\
\hline I5-PARPi & 2 & 1 & $\mathrm{H}$ & meta & $38 \%$ & $\mathrm{HBTU} / \mathrm{AcN} / \mathrm{Et}_{3} \mathrm{~N}$ \\
\hline I6-PARPi & 2 & $\mathrm{H}$ & 1 & para & $45 \%$ & $\mathrm{HBTU} / \mathrm{AcN} / \mathrm{Et}_{3} \mathrm{~N}$ \\
\hline
\end{tabular}

Fig. 2 Structure of Olaparib and iodo-PARPi inhibitors. a Molecular structure of Olaparib. b General structure of I-PARPi derivatives. c Molecular structures of I-PARPi derivatives, yields, and synthetic parameters

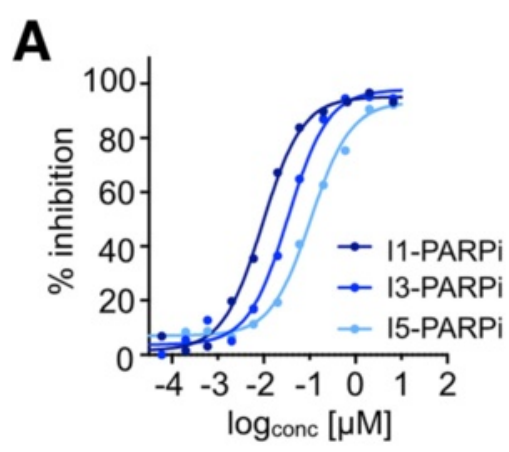

B

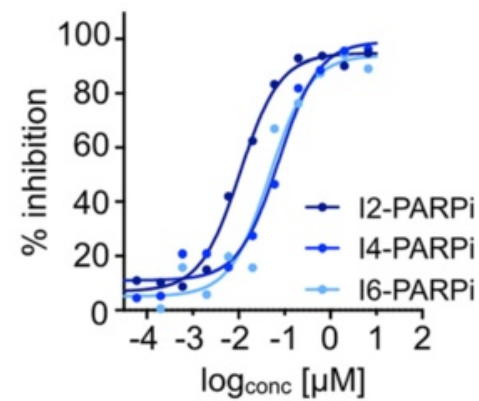

\begin{tabular}{ccccc}
\hline & IC $_{50}(\mathbf{n M})$ & $\mathbf{C H I}$ & log $\mathbf{P}_{\mathrm{CHI}}$ & Plasma Free Fraction \\
\hline $\mathbf{I 1}$ & $11 \pm 3$ & 59.6 & 2.3 & $9.6 \pm 1.5 \%$ \\
$\mathbf{I 2}$ & $9 \pm 2$ & 59.6 & 2.3 & $11.5 \pm 0.1 \%$ \\
$\mathbf{I 3}$ & $34 \pm 3$ & 66.7 & 2.7 & $7.0 \pm 0.1 \%$ \\
$\mathbf{1 4}$ & $74 \pm 5$ & 66.7 & 2.7 & $5.0 \pm 0.3 \%$ \\
$\mathbf{I 5}$ & $107 \pm 4$ & 71.6 & 3.0 & $7.8 \pm 1.4 \%$ \\
$\mathbf{1 6}$ & $47 \pm 5$ & 71.6 & 3.0 & $4.7 \pm 0.5 \%$ \\
\hline
\end{tabular}

Fig. 3 Biochemical parameters and binding affinity of iodo-PARPi derivatives. a Percent inhibition of PARP1 using a range of concentrations of the inhibitors 11-16. b Table of IC 50 values calculated from a, along with the values of chromatographic hydrophobicity index $(\mathrm{CH})$, $\log P_{\mathrm{CH}}$, and plasma free fraction 


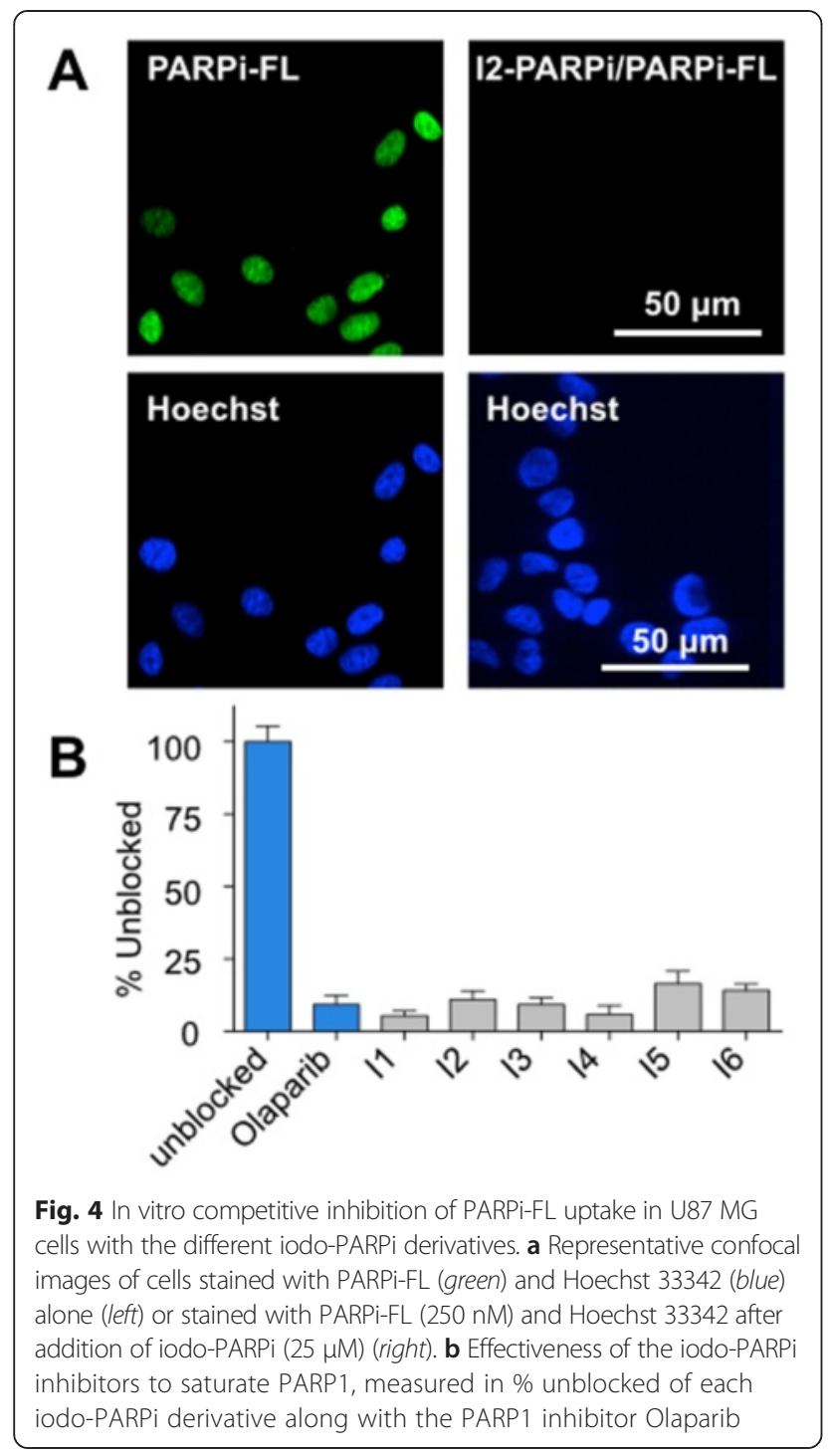

with any of the iodo-PARPi agents, a reduction in fluorescence signal between $76 \pm 6$ and $67 \pm 13 \%$ (Fig. 4b) was seen. This was similar to results obtained for Olaparib, where co-treatment resulted in a reduction of PARPi-FL uptake by $73 \pm 10 \%$.

The binding characteristics of non-radioactive I2PARPi were explored ex vivo by epifluorescence imaging of U87 MG tumor tissue. The tissue was obtained from mice that were injected with I2-PARPi before receiving an injection of PARPi-FL. A second group received PARPi-FL alone, without injection of I2-PARPi (Fig. 5a). Mice receiving both agents showed a $78 \pm 4 \%$ lower tumor fluorescence, compared with the mice receiving just PARPi-FL $\left(4.53 \times 10^{7} \pm 0.81 \times 10^{7}\right.$ and $2.03 \times 10^{8} \pm$ $1.84 \times 10^{7}$ average radiant efficiency, respectively). A control group received just PBS, and tumors from these mice did not show significant fluorescence $\left(0.42 \times 10^{6} \pm\right.$
$0.07 \times 10^{6}$ average radiant efficiency). Similar results could be seen using confocal microscopy (Fig. 5c-e), where tumors from mice injected with PARPi-FL show clear nuclear uptake in U87 MG tumors (Fig. 5c), whereas there was a significant decrease in uptake for mice which also received I2-PARPi (Fig. 5d), similar to what was observed for the control tumors (Fig. 5e).

\section{Radiolabeling and stability of $\left[{ }^{131} 1\right]-12-P A R P i$}

The preparation of the radiotracer [131I]-I2-PARPi was realized in two synthetic steps. First, the precursor $N$ succinimidyl-4-(tributylstannyl) benzoate was labeled in the presence of [131I]-NaI and chloramine $\mathrm{T}$ in acetic acid (Additional file 1: Figure S4 A) and isolated by HPLC (Additional file 1: Figure S4 C), with a radiochemical yield of $67 \pm 6 \%(n=12)$. The resulting radioactive $\mathrm{N}$-succinimidyl-4-(131I-iodo) benzoate was then conjugated to a PARP1 targeting $2 \mathrm{H}$-phthalazin-1-one in the presence of HBTU and $\mathrm{AcN}$ at room temperature (Fig. 6a). The crude mixture was purified by HPLC, yielding the pure product with a radiochemical yield of $72 \pm 8 \%(n=12)$ and a radiochemical purity $>95 \%$. HPLC chromatograms and mass spectrometry data are shown in Fig. 6b-d. For obtaining [124I]-I2-PARPi, an identical procedure was used, which results in yields of $68 \pm 5 \%(n=5)$ and a radiochemical purity $>95 \%$.

In vitro blood stability studies $\left(37^{\circ} \mathrm{C}\right)$ showed only one main peak at $15 \mathrm{~min}$, corresponding to the pure compound $\left[{ }^{131} \mathrm{I}\right]$-I2-PARPi. We did not observe other major peaks, which would indicate small molecule metabolites, which confirmed the stability of the drug over the course of $120 \mathrm{~min}$ (Additional file 1: Figure S5 A-C).

\section{In vivo pharmacokinetics of $\left[{ }^{131} \mathrm{I}\right]-\mathrm{I}$-PARPi}

We determined the blood half-life of $\left[{ }^{131} \mathrm{I}\right]-\mathrm{I} 2-\mathrm{PARPi}$ in healthy athymic nude mice (Additional file 1: Figure S6). The tracer was quickly cleared from the blood, similar to other inhibitors of this type [2, 26, 27], with an alpha blood half-life of $14.3 \mathrm{~min}(96.25 \%)$ and beta blood halflife of $94.6 \mathrm{~min}(3.75 \%)$, resulting in a weighted blood half-life of $t_{1 / 2}$ (weighted) $=17.1 \mathrm{~min}$ (Additional file 1 : Figure S6). The biodistribution of $\left[{ }^{131} \mathrm{I}\right]-\mathrm{I} 2-\mathrm{PARPi}$ was analyzed after administration of the radiolabeled tracer $(24 \pm 5 \mu \mathrm{Ci})$ in U87 MG tumor-bearing mice (Fig. 7a, b). Administration of $\left[{ }^{131} \mathrm{I}\right]-\mathrm{I} 2-\mathrm{PARPi}$ with a specific activity of $50 \mathrm{mCi} / \mu \mathrm{mol}$ showed the best tumor/muscle and tumor/brain ratios (Fig. 7a, Additional file 1: Table S1), which is why this specific activity was selected for further in vivo imaging experiments. Administration of $\left[{ }^{131} \mathrm{I}\right]-\mathrm{I} 2-\mathrm{PARPi}$ with a specific activity of $50 \mathrm{mCi} / \mu \mathrm{mol}$ showed the best tumor/muscle and tumor/brain ratios (Fig. 7a, Additional file 1: Table S1). Figure 7b compares the biodistribution of the radiotracer after different time points. The most favorable tumor/muscle and tumor/ 

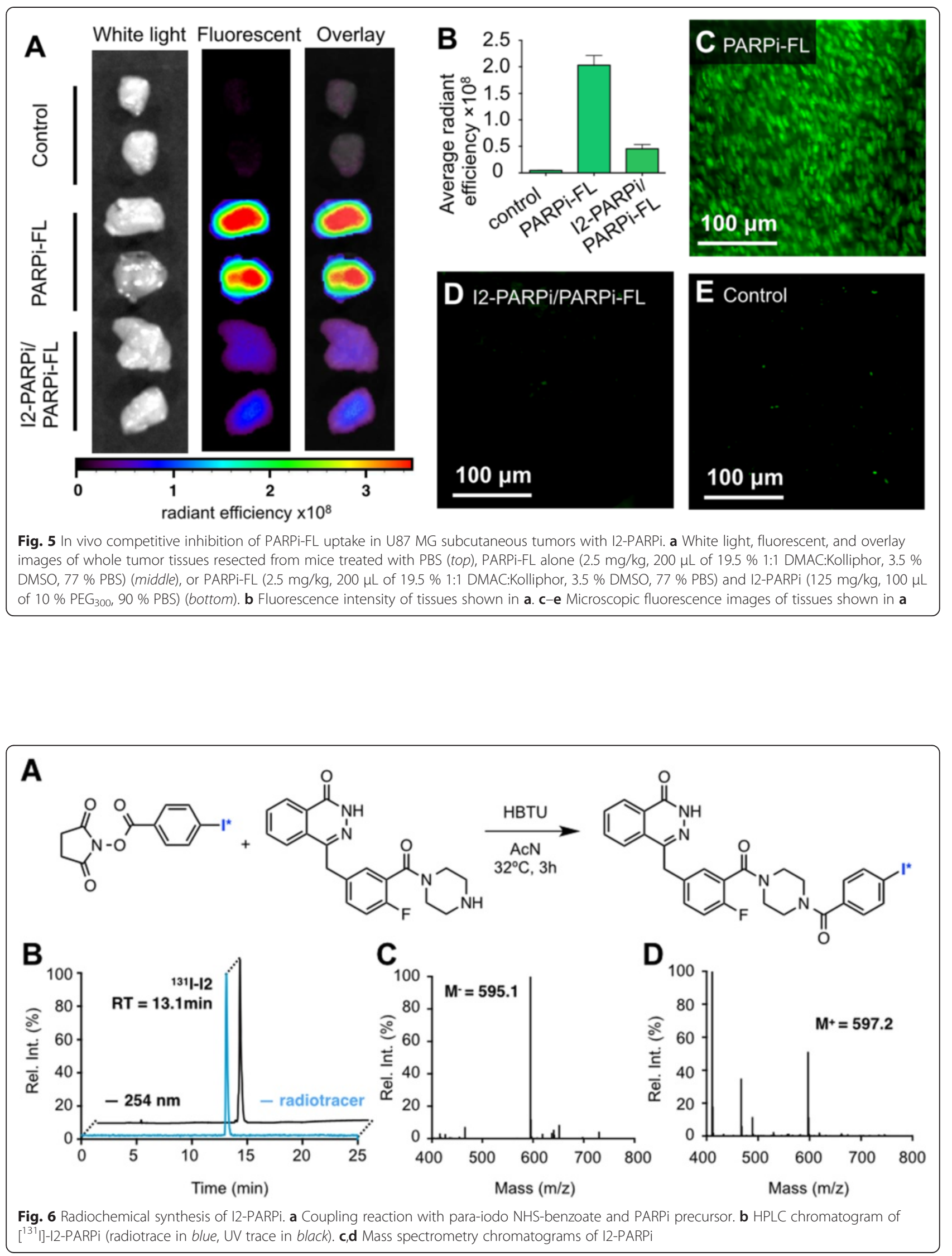

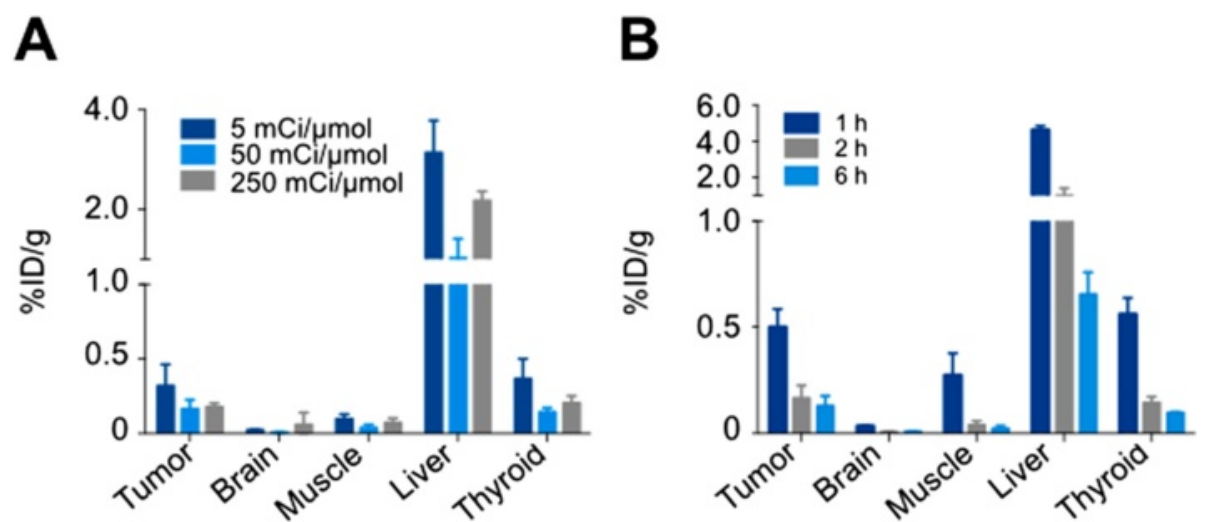

Fig. 7 Biodistribution of $\left.{ }^{[31} 1\right]-12$-PARPi in selected organs. a Comparison of the biodistribution of different specific activities of the compound $2 \mathrm{~h}$ post injection. $\mathbf{b}$ Comparison of the biodistribution of the compound at 1, 2, and $4 \mathrm{~h}$ post injection. Additional biodistribution data can be found in Additional file 1: Tables S1 and S2

brain ratios were seen at $2 \mathrm{~h}$ post intravenous injection $(0.50 \pm 0.08 \% \mathrm{ID} / \mathrm{g}, 0.04 \pm 0.02 \% \mathrm{ID} / \mathrm{g}$ and $0.007 \pm 0.002$ $\% \mathrm{ID} / \mathrm{g}$ for tumor, muscle, and brain, respectively). Figure 7 shows selected tissues, and a full biodistribution table is shown in Additional file 1: Table S2.

\section{In vivo imaging and autoradiography}

With the aim of determining the potential of radioiodinated I2-PARPi as a glioblastoma imaging agent, small animal SPECT/CT and PET/CT studies were performed in athymic nude mice bearing orthotopic U251 MG xenografts. SPECT/CT studies were performed using $\left[{ }^{131} \mathrm{I}\right]-\mathrm{I} 2-\mathrm{PARPi}$, and PET/CT studies were performed with the structural analog $\left[{ }^{124} \mathrm{I}\right]-\mathrm{I} 2-\mathrm{PARPi}$. In SPECT/ $\mathrm{CT}$, acquired $90 \mathrm{~min}$ post injection of the $\left[{ }^{131} \mathrm{I}\right]-\mathrm{I} 2$ PARPi, the orthotopic tumor could be readily visualized, with uptake of the tracer in the right hemisphere of the brain, where the tumor was implanted (Fig. 8a). This data is also supported by ex vivo autoradiography. Histological sections of orthotopic U251 MG tumors showed a clear delineation of tumor tissue with $\left[{ }^{131} \mathrm{I}\right]-\mathrm{I} 2-\mathrm{PARP}$, but not for mice where PARP1 was saturated with a preinjection of the non-labeled PARP1 inhibitor Olaparib (Fig. 8b). The signal intensity of $\left[{ }^{131} \mathrm{I}\right]-\mathrm{I} 2-\mathrm{PARPi}$ in tumor tissue of mice that received no Olaparib was 15.7-fold higher than healthy brain tissue (Fig. 8c) and 6.2-fold higher than muscle tissue (Fig. 8d), corroborating the SPECT data. There was a $65 \%$ reduction in the intensity of the autoradiography signal in tumor tissue for mice that had been treated with Olaparib (1222 \pm 203 and $536 \pm 87$ AU for mice without and with Olaparib treatment, respectively), further verifying the specificity of the compound. In contrast, the intensity of the muscle did not undergo statistically significant changes (192 \pm 20 and $248 \pm 72 \mathrm{AU}$ for mice without and with Olaparib treatment, respectively, Fig. 8d).
PET/CT data was obtained after intravenous injection 180-230 $\mu \mathrm{Ci}$ of $\left[{ }^{124} \mathrm{I}\right]-\mathrm{I} 2-\mathrm{PARPi}(110-170 \mathrm{mCi} / \mu \mathrm{mol})$. Similar to SPECT/CT, orthotopic U251 MG xenografts were clearly visualized non-invasively, whereas healthy mice showed negligible uptake of the tracer (Fig. 9a). Ex vivo biodistribution data with $\left[{ }^{131} \mathrm{I}\right]-\mathrm{I} 2-\mathrm{PARPi}$ corroborated the $\mathrm{PET} / \mathrm{CT}$ data (Fig. $9 \mathrm{~b}$ and Additional file 1: Table. S3A). Comparably to U87 MG, we determined the tumor uptake in U251 MG to be $0.43 \pm 0.05 \% \mathrm{ID} / \mathrm{g}$, whereas only a minute amount of tracer was retained in the healthy brain $(0.011 \pm 0.003 \% \mathrm{ID} / \mathrm{g})$. High uptake was observed in the liver $(2.4 \pm 0.6 \% \mathrm{ID} / \mathrm{g})$, which is common for intravenously administered small molecules that are excreted hepatobiliary. The tumor/brain ratio was found to be $40.0 \pm 6.3$, and the tumor/muscle ratio was $13.7 \pm 4.1$ (Fig. 9c and Additional file 1: Table S3B) indicating potential clinical value of the tracer.

\section{Discussion and conclusions}

Glioblastoma multiforme (GBM) is characterized by aggressive malignant infiltrative growth and is associated with a dismal prognosis [28]. Current standard of care for non-invasive glioblastoma diagnosis is MRI [29, 30], which often offers acceptable information regarding the size and shape of the tumor. However, this tool is often unable to characterize the underlying histopathology of the disease. Better and more accurate tools are therefore desperately needed, particularly for detecting glioblastoma at low levels of infiltration [8]. The first step of this work was the development of a library of novel, iodinated small molecules, which are targeted to PARP1 via their 2H-phthalazin-1-one group. Biochemical assays and basic pharmacokinetic evaluation showed that some of the small molecules had $\mathrm{IC}_{50}$ values close to $10 \mathrm{nM}$ $(9 \pm 2 \mathrm{nM}$ and $11 \pm 3 \mathrm{nM}$ for I2-PARPi and I1-PARPi), which is close to the original Olaparib [22] and lower 


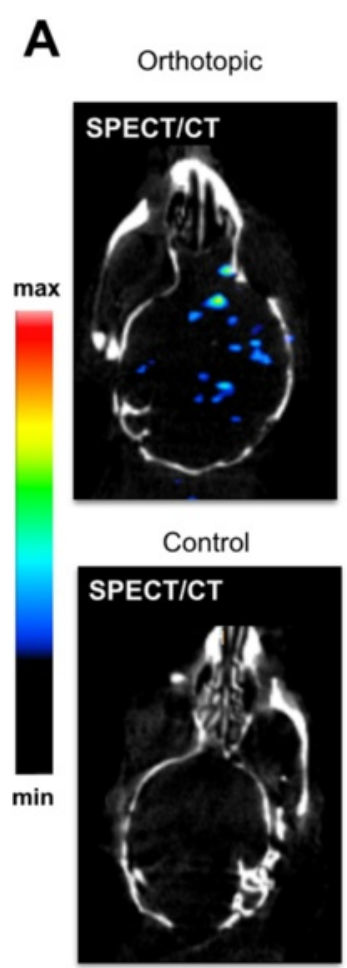

B
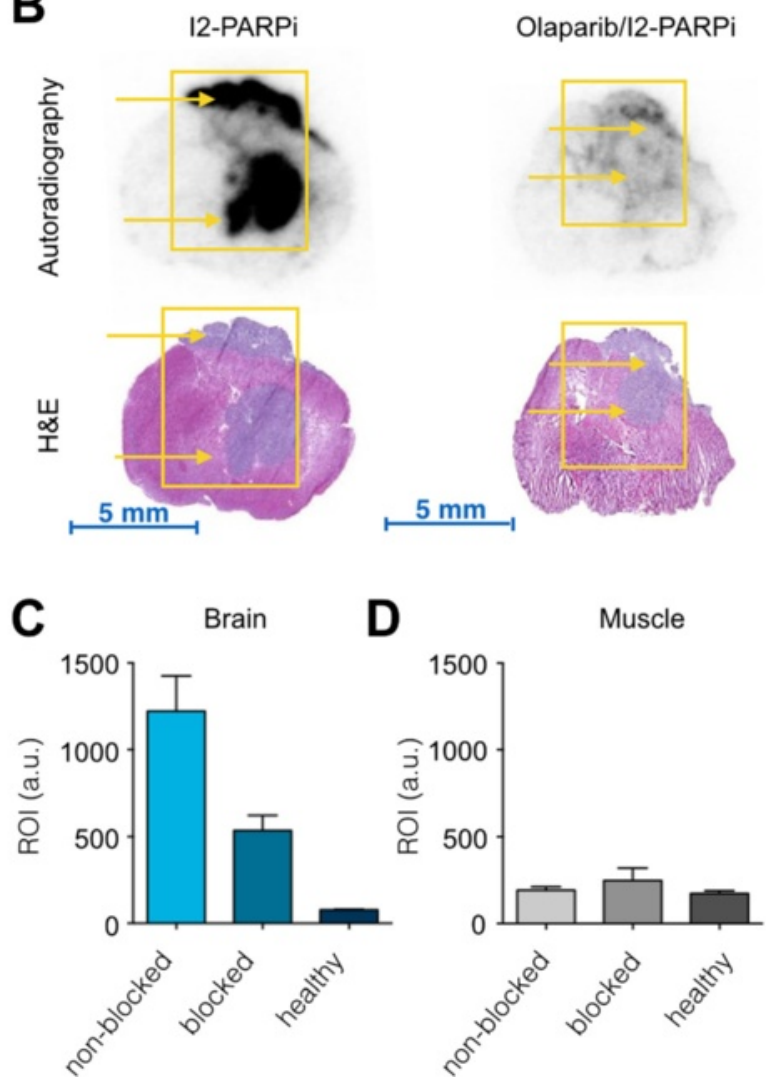

Fig. 8 Uptake of $\left[{ }^{131} 1\right]$-I2-PARPi in orthotopic U251 MG brain tumors. a SPECT/CT images of a mouse bearing an orthotopic U251 MG brain tumor (top) and a healthy mouse treated with [ ${ }^{131} 1$ ]-I2-PARPi (bottom). b Autoradiography and H\&E stains of ex vivo brain sections from orthotopic U251 MG brain tumor mice. Mice were treated with [ $\left.{ }^{131} 1\right]$-I2-PARPi alone (left) or $\left[{ }^{131} \mathrm{I}\right]$-I2-PARPi with a pre-injection of Olaparib (right). Yellow arrows point towards the tumors. $\mathbf{c}$, d Quantification of [ $\left.{ }^{131}{ }^{1}\right]$-I2-PARPi uptake in brain or muscle in non-blocked, blocked, and healthy mice

than other well-performing in vivo PARP1 imaging agents [26, 27]. The small molecule I2-PARPi, derived from 4-iodobenzoic acid, demonstrated the best in vitro PARP1 binding and the optimal biophysical properties for further use in in vivo $\left(\mathrm{IC}_{50}=9 \pm 2 \mathrm{nM}, \mathrm{CHI}=59.6\right.$, $\log P_{\mathrm{CHI}}$, plasma free fraction $=11.5 \pm 0.1 \%$; Fig. $3 \mathrm{~b}$ ). These pharmacokinetic properties were complemented in vitro and in vivo by competition studies of the nonradiolabeled I2-PARPi and the fluorescent PARPi-FL $[26,27]$. Fluorescence-based in vitro assays confirmed selective nuclear accumulation of all our compounds in U87 MG glioblastoma cells (Fig. 5), where uptake of a fluorescent PARP1 inhibitor was inhibited in the presence of the iodo-PARP1 agents, leading to a significant reduction in nuclear fluorescence intensity between $76 \pm 6$ and $67 \pm 13 \%$. This reduction was comparable to the parent scaffold Olaparib $(73 \pm 11 \%)$. Similarly, in vivo injection of I2-PARPi reduced the uptake of the fluorescent probe equally well, confirming the ability of the iodinated small molecule to bind to PARP1, and to target the enzyme inside of cell nuclei. The radiolabeled analog of this inhibitor was obtained through nucleophilic substitution of the $\left(\mathrm{Bu}_{3}\right) \mathrm{Sn}$ labeled cold precursor with ${ }^{131} \mathrm{I}$ or ${ }^{124} \mathrm{I}$ in mild conditions with a specific activity between 145-210 and 110-170 $\mathrm{mCi} / \mu \mathrm{mol}$ for $\left[{ }^{131} \mathrm{I}\right]-\mathrm{I} 2-\mathrm{PARPi}$ and $\left[{ }^{124} \mathrm{I}\right]-\mathrm{I} 2-$ PARPi, respectively (Fig. 4a). The tracer showed a weighted blood half-life $t_{1 / 2}$ of $17.1 \mathrm{~min}$ (Additional file 1: Figure S6), a typical pharmacokinetic profile for small molecules, which matches up with values obtained for other Olaparib derivatives $[2,23]$. In vivo biodistribution studies of $\left[{ }^{131} \mathrm{I}\right]-\mathrm{I} 2-\mathrm{PARPi}$ in U251 MG subcutaneous xenograft models (Additional file 1: Table S3) confirmed rapid clearance from all organs via the liver $(2.3 \pm$ $0.6 \% \mathrm{ID} / \mathrm{g}$; Fig. 9c). A significant accumulation of the tracer in glioblastoma tissue $(0.43 \pm 0.05 \% \mathrm{ID} / g$; Fig. 9c) compared to other control tissues like brain $(0.011 \pm$ $0.003 \% \mathrm{ID} / \mathrm{g})$ or muscle $(0.033 \pm 0.012 \% \mathrm{ID} / \mathrm{g})$ was observed, leading to a signal/noise ratio of $40.05 \pm 6.34$ (Fig. 9d), ideal for in vivo imaging. The difference in tumor to brain uptake was also verified by autoradiography, 

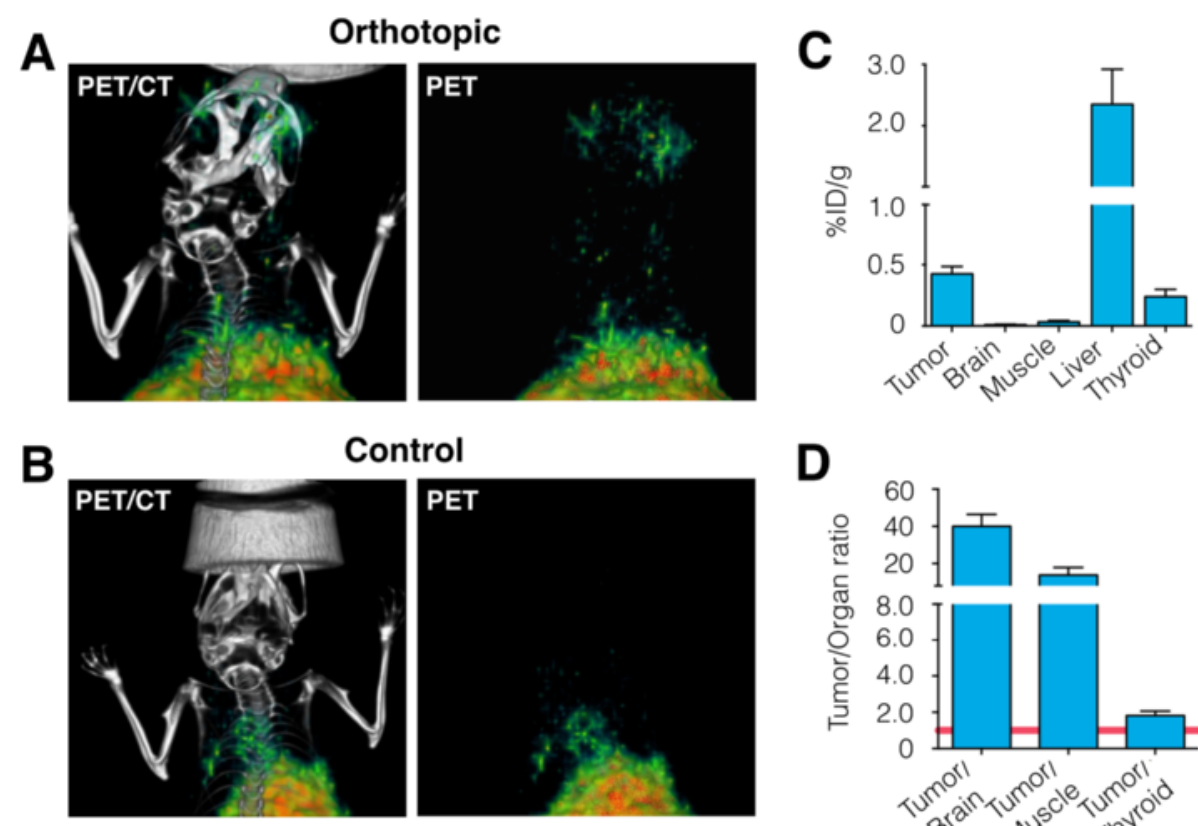

D

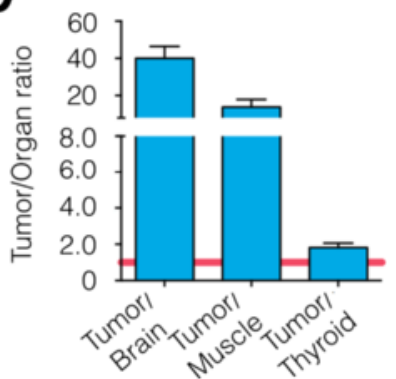

Fig. 9 PET imaging of orthotopic brain tumors with [ $\left.{ }^{124} 1\right]-12$-PARPi. a PET/CT coronal images (left) and corresponding PET images (right) of orthotopic U251 MG brain tumor mice injected with [ [24|]-I2-PARPi. b PET/CT coronal images (left) and corresponding PET images (right) of a healthy mouse treated with $\left[{ }^{124} \mathrm{l}\right]$-I2-PARPi. c Biodistribution of [ $\left.{ }^{131} \mathrm{l}\right]-12$-PARPi in a U251 MG xenograft mouse model (mice were sacrificed $2 \mathrm{~h}$ after tracer injection, additional biodistribution data can be found in Additional file 1: Tables S3A and S3B). d Selected tumor to non-target tissues ratios of $\left[{ }^{131} \mathrm{I}\right]-$ I2-PARPi. Radioactivity in tissues is expressed as \%ID/g

where the $\left.{ }^{131} \mathrm{I}\right]-$ I2-PARPi uptake was 15.7 -fold higher than that in the healthy brain tissue (Fig. 8b). At the same time, the PARP1 specificity of our tracer was confirmed after treatment with the PARP1 inhibitor Olaparib (Fig. 8c) showing a significant drop in signal intensity. The potential value of I2-PARPi as a tracer for clinical imaging of glioblastoma was corroborated in an orthotopic U251 MG glioblastoma mouse model by both SPECT/CT and PET/ CT imaging (Figs. 8 and 9), where a clear accumulation of the tracer in the tumor tissue could be observed.

In summary, we have designed, radiolabeled, and tested a library of iodinated PARP1 inhibitors, based on the high affinity of PARP1 to the 2H-phthalazin-1-one scaffold. The high tolerability of PARP1 for small molecules appended to $2 \mathrm{H}$-phthalazin-1-one resulted in a number of high affinity binders in our small molecule library, the best representative of which, $\left[{ }^{124 / 131} \mathrm{I}\right]-\mathrm{I} 2-$ PARPi, was tested as a PET and SPECT tracer. Our data demonstrates the specific binding of our I2-PARPi tracer to PARP1 and illustrates the potential of this tracer for glioblastoma detection.

\section{Additional file}

Additional file 1: Supporting information. This file contains supplemental figures S1 to S6 and supplementary tables S1 to S3. (DOCX $661 \mathrm{~kb}$ )

\section{Abbreviations}

AcN: acetonitrile; CHI: chemical hydrophobicity index; EDC: 1-ethyl-3-(3dimethylaminopropyl) carbodiimide; HBTU: $N, N, N^{\prime}, N^{\prime}$-tetramethyl-O- $(1 \mathrm{H}-$ benzotriazol-1-yl) uronium hexafluorophosphate; NHS: N-hydroxysuccinimide.

\section{Competing interests}

The authors declare that they have no competing interests.

\section{Authors' contributions}

BS and TR designed the experiments and analyzed and interpreted the data. $B S, C P I, S K$, and AB carried out the experiments. NP, GC, and WW interpreted data. BS and TR wrote the manuscript. All authors read, provided feedback on, and approved the manuscript.

\section{Aknowledgements}

The authors thank Dr. Jason S. Lewis, Dr. Christian Brand, and Dr. Carlos Pérez-Medina for helpful discussions. The authors further thank the Animal Imaging Core Facility, the Radiochemistry \& Molecular Imaging Probe Core as well as the Molecular Cytology Core at Memorial Sloan Kettering Cancer Center (P30 CA008748). Last, the authors thank the NIH (K25 EB016673), the Brain Tumor Center of MSK, and the Imaging and Radiation Sciences Program for their generous funding. In addition, the authors also wish to thank Mr. Michael Beal for his help with small molecule synthesis and characterization and Mrs. Valerie Longo for her help with animal experiments.

\section{Author details}

'Department of Radiology, Memorial Sloan Kettering Cancer Center, 1275 York Avenue, New York, NY 10065, USA. ${ }^{2}$ Program in Chemical Biology, Memorial Sloan Kettering Cancer Center, New York, NY 10065, USA. ${ }^{3}$ Weill Cornell Medical College, New York, NY 10065, USA. 


\section{References}

1. Wen PY, Kesari S. Malignant gliomas in adults. N Engl J Med. 2008;359:492-507.

2. Irwin CP, Portorreal $Y$, Brand $C$, Zhang $Y$, Desai $P$, Salinas B, et al. PARPiFL—a fluorescent PARP1 inhibitor for glioblastoma imaging. Neoplasia. 2014;16:432-40.

3. Weissleder R, Pittet MJ. Imaging in the era of molecular oncology. Nature. 2008:452:580-9.

4. Kalpathy-Cramer J, Gerstner ER, Emblem KE, Andronesi OC, Rosen B. Advanced magnetic resonance imaging of the physical processes in human glioblastoma. Cancer Res. 2014;74:4622-37.

5. Yoon J, Kim J-h, Kang W, Sohn C-H, Choi S, Yun T, et al. Grading of cerebral glioma with multiparametric MR imaging and 18F-FDG-PET: concordance and accuracy. Eur Radiol. 2014;24:380-9.

6. Santra A, Kumar R, Sharma P, Bal C, Kumar A, Julka PK, et al. F-18 FDG PET$C T$ in patients with recurrent glioma: comparison with contrast enhanced MRI. Eur J Radiol. 2012;81:508-13.

7. Sorensen AG, Batchelor TT, Wen PY, Zhang WT, Jain RK. Response criteria for glioma. Nat Clin Pract Oncol. 2008;5:634-44.

8. Xie Q, Mittal S, Berens ME. Targeting adaptive glioblastoma: an overview of proliferation and invasion. Neurooncology. 2014;16:1575-84

9. Gradwohl G, Ménissier de Murcia JM, Molinete M, Simonin F, Koken M, Hoeijmakers $\mathrm{JH}$, et al. The second zinc-finger domain of poly(ADP-ribose) polymerase determines specificity for single-stranded breaks in DNA. Proc Natl Acad Sci U S A. 1990;87:2990-4.

10. Hassa PO, Hottiger MO. The diverse biological roles of mammalian PARPS, a small but powerful family of poly-ADP-ribose polymerases. Front Biosci. 2008:13:3046-82.

11. Rouleau M, Patel A, Hendzel MJ, Kaufmann SH, Poirier GG. PARP inhibition: PARP1 and beyond. Nat Rev Cancer. 2010;10:293-301.

12. Kraus WL, Hottiger MO. PARP-1 and gene regulation: progress and puzzles. Mol Aspects Med. 2013;34:1109-23.

13. Burkle A, Virag L. Poly(ADP-ribose): PARadigms and PARadoxes. Mol Aspects Med. 2013;34:1046-65.

14. Jagtap P, Szabo C. Poly(ADP-ribose) polymerase and the therapeutic effects of its inhibitors. Nat Rev Drug Discov. 2005;4:421-40.

15. Schreiber V, Dantzer F, Ame JC, de Murcia G. Poly(ADP-ribose): nove functions for an old molecule. Nat Rev Mol Cell Biol. 2006;7:517-28.

16. Ossovskaya V, Koo IC, Kaldjian EP, Alvares C, Sherman BM. Upregulation of poly (ADP-Ribose) polymerase-1 (PARP1) in triple-negative breast cancer and other primary human tumor types. Genes Cancer. 2010;1:812-21.

17. Rojo F, Garcia-Parra J, Zazo S, Tusquets I, Ferrer-Lozano J, Menendez S, et al. Nuclear PARP-1 protein overexpression is associated with poor overall survival in early breast cancer. Ann Oncol. 2012;23:1156-64.

18. Alanazi M, Pathan AA, Abduljaleel Z, Shaik JP, Alabdulkarim HA, Semlali A, et al. Association between PARP-1 V762A polymorphism and breast cancer susceptibility in Saudi population. PLoS One. 2013:8:e85541.

19. Galia A, Calogero AE, Condorelli RA, Fraggetta F, La Corte C, Ridolfo F, et al PARP-1 protein expression in glioblastoma multiforme. Eur J Histochem. 2012;56:59.

20. Barton VN, Donson AM, Kleinschmidt-DeMasters BK, Gore L, Liu AK, Foreman NK. PARP1 expression in pediatric central nervous system tumors. Pediatr Blood Cancer. 2009;53:1227-30.

21. Staibano S, Pepe S, Muzio LL, Somma P, Mascolo M, Argenziano G, et al. Poly(adenosine diphosphate-ribose) polymerase 1 expression in malignant melanomas from photoexposed areas of the head and neck region. Hum Pathol. 2005;36:724-31

22. Menear KA, Adcock C, Boulter R, Cockcroft X-I, Copsey L, Cranston A, et al. 4-[3-(4-Cyclopropanecarbonylpiperazine-1-carbonyl)-4-fluorobenzyl]-2Hphthalazin-1-one: a novel bioavailable inhibitor of poly(ADP-ribose) polymerase-1. J Med Chem. 2008;51:6581-91.

23. Carlucci G, Carney B, Brand C, Kossatz S, Irwin C, Carlin S, et al. Dual-modality optical/PET imaging of PARP1 in glioblastoma. Mol Imaging Biol. 2015:123(2):289-97.

24. Valkó K, Bevan C, Reynolds D. Chromatographic hydrophobicity index by fast-gradient RP-HPLC: a high-throughput alternative to log P/log D. Anal Chem. 1997:69:2022-9.

25. Reiner T, Lacy J, Keliher EJ, Yang KS, Ullal A, Kohler RH, et al. Imaging therapeutic PARP inhibition in vivo through bioorthogonally developed companion imaging agents. Neoplasia. 2012;14:169-77.
26. Reiner T, Lacy J, Keliher EJ, Yang KS, Ullal A, Kohler RH, et al. Imaging therapeutic PARP inhibition in vivo through bioorthogonally developed companion imaging agents. Neoplasia (New York, NY). 2012;14:169-77.

27. Thurber GM, Yang KS, Reiner T, Kohler RH, Sorger P, Mitchison T, et al. Single-cell and subcellular pharmacokinetic imaging allows insight into drug action in vivo. Nat Commun. 2013:4:1504

28. Stupp R, Hegi ME, Mason WP, van den Bent MJ, Taphoorn MJB, Janzer RC, et al. Effects of radiotherapy with concomitant and adjuvant temozolomide versus radiotherapy alone on survival in glioblastoma in a randomised phase III study: 5-year analysis of the EORTC-NCIC trial. Lancet Oncol. 2009;10:459-66

29. Ideguchi M, Kajiwara K, Goto H, Sugimoto K, Nomura S, Ikeda E, et al MRI findings and pathological features in early-stage glioblastoma. J Neurooncol. 2015;123(2):1-9.

30. Wu C-X, Lin G-S, Lin Z-X, Zhang J-D, Liu S-Y, Zhou C-F. Peritumoral edema shown by MRI predicts poor clinical outcome in glioblastoma. World J Surg Oncol. 2015:13:97.

\section{Submit your manuscript to a SpringerOpen ${ }^{\circ}$ journal and benefit from:}

- Convenient online submission

- Rigorous peer review

- Immediate publication on acceptance

- Open access: articles freely available online

- High visibility within the field

- Retaining the copyright to your article

Submit your next manuscript at springeropen.com 